\title{
Proteomic Analysis of Fasciola hepatica Excretory and Secretory Products Co-Immunoprecipitated Using Time Course Infection Sera
}

\author{
Zhuo Lan ${ }^{1,2}$, Xiao-Lei Liu ${ }^{3}$, Qing-Bo Lv ${ }^{1,2}$, Min-Hao Zeng ${ }^{1,2}$, Jun-Feng Gao ${ }^{1,2}$, Qiao-Cheng Chang ${ }^{1,2}$, \\ Yuan-Yuan Chen ${ }^{1, *}$ and Chun-Ren Wang ${ }^{1,2}$ \\ 1 College of Animal Science and Veterinary Medicine, Heilongjiang Bayi Agricultural University, \\ Daqing 163319, China; zhuolan@byau.edu.cn (Z.L.); qingbolv@byau.edu.cn (Q.-B.L.); \\ zengminhao@stu.just.edu.cn (M.-H.Z.); gaojunfeng@byau.edu.cn (J.-F.G.); qcchang@stu.edu.cn (Q.-C.C.); \\ chunrenwang@byau.edu.cn (C.-R.W.) \\ 2 Heilongjiang Provincial Technology Innovation Center for Bovine Disease Control and Prevention, \\ Daqing 163319, China \\ 3 Key Laboratory of Zoonosis Research, Ministry of Education, Institute of Zoonosis, \\ College of Veterinary Medicine, Jilin University, Changchun 130012, China; liuxlei@jlu.edu.cn \\ * Correspondence: chenyuanyuan@byau.edu.cn
}

check for updates

Citation: Lan, Z.; Liu, X.-L.; Lv, Q.-B.; Zeng, M.-H.; Gao, J.-F.; Chang, Q.-C.; Chen, Y.-Y.; Wang, C.-R. Proteomic Analysis of Fasciola hepatica Excretory and Secretory Products

Co-Immunoprecipitated Using Time Course Infection Sera. Pathogens 2021 10, 749. https://doi.org/ 10.3390 / pathogens10060749

Academic Editors: Mark Robinson and Krystyna Cwiklinski

Received: 10 April 2021

Accepted: 11 June 2021

Published: 13 June 2021

Publisher's Note: MDPI stays neutra with regard to jurisdictional claims in published maps and institutional affiliations.

Copyright: (c) 2021 by the authors. Licensee MDPI, Basel, Switzerland. This article is an open access article distributed under the terms and conditions of the Creative Commons Attribution (CC BY) license (https:// creativecommons.org/licenses/by/ $4.0 /$ )

Abstract: Fasciola hepatica is a widespread pathogen that is known for its harmful effects on the health and productivity of ruminant animals. To identify the proteins present in all periods of infection with F. hepatica but not in those with Fasciola gigantica by shotgun liquid chromatography-tandem mass spectrometry (LC-MS/MS), we collected the ESPs and sera of F. hepatica and F. gigantica. In this study, the sheep were artificially infected with F. hepatica and the sera were collected at five different periods: 3 days post-infection (dpi), $7 \mathrm{dpi}, 21 \mathrm{dpi}, 63 \mathrm{dpi}$, and $112 \mathrm{dpi}$. The interacting proteins were pulled down from the sheep sera of all five periods and the sera with F. gigantica by co-immunoprecipitation (Co-IP) assay, before being identified by LC-MS/MS analysis. Thirty, twenty-two, twenty-three, twenty-seven, and twenty-two proteins were pulled down by the infected sera at $3 \mathrm{dpi}, 7 \mathrm{dpi}, 21 \mathrm{dpi}$, $63 \mathrm{dpi}$, and $112 \mathrm{dpi}$, respectively. Among them, 12 proteins existed in all periods, while six proteins could be detected in all periods in F. hepatica but not in F. gigantica. Protein relative pathway analysis revealed that these proteins mainly refer to the metabolism, regulation of genetic activity, and signal transduction of F. hepatica. In conclusion, this study provides meaningful data for the diagnosis of fasciolosis and to understand the interactions between F. hepatica and the host.

Keywords: Fasciola hepatica; Fasciola gigantica; excretory and secretory products; Co-IP

\section{Introduction}

Fasciola hepatica mainly parasitizes the liver and bile ducts of ruminant animals and humans, causing fasciolosis. Fasciolosis is widely seen in Europe, Asia, America, and Africa and is also observed in other areas of the world [1]. It is estimated to cause annual economic losses >USD 3.2 billion dollars worldwide [2]. F. hepatica can cause acute and chronic hepatitis and cholangitis in animals, accompanied by systemic poisoning and nutritional disorders. When cattle and sheep are infected with F. hepatica, there is a decrease in the quality of their biological products and milk yield, which poses a remarkable threat to animal husbandry [3]. Humans are also at risk of fasciolosis, with approximately 2.6 million infected people globally [4]. Helminths are powerful immunoregulators. Excretory and secretory products (ESPs) are a mixture of proteins, lipids and carbohydrates which are secreted and excreted by the parasites (either soluble secreted proteins or those packaged within extracellular vesicles) and those expressed on the outer surface of the tegument during parasitism of the host [5]. Antigenic stimulation is an important initiating factor for the generation, maintenance, and regulation of host immune responses. As worms from 
different sources have their own specific antigen components, the mechanisms of action and host immune responses in them are not identical [6]. Antigens are directly exposed to the host immune system. ESPs are not only one of the main antigens that stimulate humoral and cell-mediated immunity, but they also play important roles in the survival of parasites and host-parasite interactions [7]. Compared to the antigens, ESPs of flukes have better sensitivity and specificity, and the antibody levels in hosts are positively correlated with the severity of infection caused by the flukes [8,9]. Proteomics and bioinformatics can be used to analyze the dynamic changes in excretory and secretory proteins expressed in different periods of infection, which can provide information for the screening and identification of important antigen molecules which may be related to the induction of host immune responses, immune regulation, immune escape, etc. Using proteomics approaches based on mass spectrometry, the protein composition of ESPs has been characterized in several species, including Haemonchus contortus, Heligmosomoides polygyrus, Ascaris suum, and Nippostrongylus brasiliensis [10-12]. Scholars have studied the changes of protein components in small cell lung cancer H446 cells treated with ESPs of Trichinella spiralis by LC-MS/MS, and showed that the anti-tumor mechanism of ESPs and their processes are complex [13]. Gourbal and Jefferies performed proteomic analysis of the F. hepatica excretory and secretory products (FhESPs), and Jefferies identified 29 proteins, including cathepsin L and proteins related to immune escape. Global data on the components, proportion, and relative abundance of FhESPs have also been analyzed [14,15]. Moreover, some learners take proteomic analysis of Fasciola gigantica ESPs interacting with the buffalo serum of different infection periods by shotgun LC-MS/MS, and they identified some proteins which provides material for studies about the interaction between Fasciola gigantica and host [16]. However, given the difficulty in obtaining parasites at different developmental stages and the fact that these parasites can excrete or secrete different antigens during different stages of their development in the host, information regarding FhESPs is still very limited. Fortunately, we can address these limitations owing to a recent report on the Fasciola genome and associated transcriptome datasets [17]. In addition, there is the other Fasciola genome which improved annotation for the trematode Fasciola hepatica [18]. We can also perform a definitive characterization of the total antigenic targets of adult F. hepatica in different infection periods.

The purpose of this study was to identify the antigenic targets in FhESPs using an immunoproteomic approach. The immunoprecipitants were analyzed and characterized using liquid chromatography-tandem mass spectrometry (LC-MS/MS). This approach can be used to analyze specific proteins and provide a reliable basis for the screening of diagnostic antigens of F. hepatica.

\section{Materials and Methods}

\subsection{FhESPs Preparation}

FhESPs were prepared according to the standard procedure previously described by Novobilsky et al. [19]. Adults of F. hepatica were separated from the liver and washed three times in phosphate-buffered saline (PBS) to remove the host material. The flukes were then incubated in sterile RMPI 1640 medium with the addition of antibiotics and antimycotic $\left(10,000 \mathrm{UI} / \mathrm{mL}\right.$ penicillin $\mathrm{G}, 10 \mathrm{mg} / \mathrm{mL}$ amphotericin B) at $37^{\circ} \mathrm{C}$ for $2 \mathrm{~h}$. F. hepatica was then transferred into a new medium with the same RMPI 1640 and incubated for $23 \mathrm{~h}$ at $37^{\circ} \mathrm{C}$. The supernatant was obtained at $5 \mathrm{~h}, 11 \mathrm{~h}$ and $23 \mathrm{~h}$ centrifuged $(13,400 \times g$ for $20 \mathrm{~min})$, they were combined then stored at $-80^{\circ} \mathrm{C}$ until further use.

\subsection{Preparation of Serum}

Six sheep were selected from Daqing, Heilongjiang Province, China. All animal studies were performed in accordance with the Guide for the Care and Use of Laboratory Animals (1996). This study was approved by the Animal Health, Animal Care and Use Committee of Heilongjiang BAYI Agricultural University. Ivermectin and albendazole were orally administered for one month. F. hepatica metacercariae were obtained from the 
eggs from naturally infected sheep in Heilongjiang, China. Wet lettuce leaves with 220 metacercaria were wrapped into a mass to keep them moist and then randomly fed to three sheep with a mouth opener. The sheep were also given some water to ensure that they swallowed the metacercaria along with the lettuce leaves. After 60 days of infection, the feces of infected sheep were collected for fecal examination. At 3, 7, 21, 63, and 112 dpi, blood samples were aseptically collected from animal into tubes without anticoagulants. The sera were separated by centrifugation and preserved at $-80^{\circ} \mathrm{C}$ for further use. We selected the positive serum of different periods from all the positive sera of three infected sheep. We obtained the negative serum from the other three sheep at 21 days, 63 days and 112 days, which were uninfected. The F. gigantica serum at $21 \mathrm{dpi}, 63 \mathrm{dpi}$ and $112 \mathrm{dpi}$ of three sheep were obtained from the Laboratory Animal Center of Lanzhou Veterinary Research Institute, Chinese Academy of Agriculture Sciences. The F. gigantica serum of each sheep at different stages were pooled separately. Target proteins that interacted with the positive serum of sheep at different infection stages and F. gigantica serum of sheep were pulled down by co-immunoprecipitation (Co-IP).

\subsection{Co-IP of FhESPs-Antibody Binding Proteins}

The Protein A/G PLUS Agarose immunoprecipitation kit (Santa Cruz Biotechnology, USA) was used for Co-IP according to the manufacturer's instructions. Additionally, the Co-IP was performed in biological triplicate. The sheep normal serum and the serum at $3 \mathrm{dpi}, 7 \mathrm{dpi}, 21 \mathrm{dpi}, 63 \mathrm{dpi}$, and $112 \mathrm{dpi}$, as well as the F. gigantica serum, were placed on ice and diluted with $200 \mu \mathrm{L}$ PBS. The $30 \mu \mathrm{L}$ protein A/G plus agarose beads were washed three times with $200 \mu \mathrm{L}$ PBS buffer, divided into 21 tubes, added to the samples and incubated at $4{ }^{\circ} \mathrm{C}$ for $1 \mathrm{~h}$ and centrifuged at $1000 \times g$ for $30 \mathrm{~s}$. Thereafter, the supernatant was carefully discarded and the beads were washed three times with $200 \mu \mathrm{L}$ PBS buffer. The FhESPs were filtered and concentrated, and the immunoprecipitation (IP) lysate was added for cleavage and quantification. Subsequently, $500 \mu \mathrm{g}$ FhESPs was added to the protein A/G beads along with $500 \mu \mathrm{L}$ PBS. The beads were then incubated at $4{ }^{\circ} \mathrm{C}$ for $1.5 \mathrm{~h}$ and centrifuged at $1000 \times g$ for $30 \mathrm{~s}$. The supernatant was discarded and the beads were washed three times with $200 \mu \mathrm{L}$ PBS buffer. Thereafter, $20 \mu \mathrm{L} 5 \times$ SDS-loading was added and the mixture was centrifuged at $95^{\circ} \mathrm{C}$ for $10 \mathrm{~min}$, and then centrifuged at $1000 \times \mathrm{g}$ for $30 \mathrm{~s}$ to collect the supernatant. Fifteen micrograms of each sample was analyzed by sodium dodecyl sulfate-polyacrylamide gel electrophoresis (SDS-PAGE).

\subsection{In-Gel Trypsin Digestion}

The gel in each lane was cut into pieces of $1 \mathrm{~mm}^{3}$ with a scalpel, placed into different $1.5 \mathrm{~mL}$ tubes, and washed with $200 \mu \mathrm{L}$ distilled water twice, for $10 \mathrm{~min}$ each time. The dye decolorizing solution (50 mm NH $\mathrm{mHCO}_{3}$ and $\mathrm{ACN}$ 1:1) was then added for $15 \mathrm{~min}$ and washed with double distilled water. This was repeated three times until the decolorization was complete. A $100 \mu \mathrm{L}$ volume of acrylonitrile (ACN) was added to dehydrate the solution until the colloidal particles turned white and vacuum was added for 10 min to make it dry. Thereafter, $200 \mu \mathrm{L}$ of $10 \mathrm{mM}$ dithiothreitol (DTT) $\left(25 \mathrm{mM} \mathrm{NH}_{4} \mathrm{HCO}_{3}\right.$ dissolved) was added and placed in a water bath at $37^{\circ} \mathrm{C}$ for $1 \mathrm{~h}$. Then, $100 \mu \mathrm{L}$ ACN was added to dehydrate the solution until the colloidal particles turned white and $200 \mu \mathrm{L}$ of 55 mM IAA ( $25 \mathrm{mM}$ $\mathrm{NH}_{4} \mathrm{HCO}_{3}$ dissolved) was added. It was placed in the dark room for $30 \mathrm{~min}$. Then, $100 \mu \mathrm{L}$ $\mathrm{ACN}$ was added to dehydrate the solution until the colloidal particles turned white and the suspension was successively washed with double distilled water, ACN for $10 \mathrm{~min}$ for each liquor, finally washed with double distilled water for $10 \mathrm{~min}$ again. Then, $100 \mu \mathrm{L}$ of $0.01 \mu \mathrm{g} / \mu \mathrm{L}$ trypsin working solution (the enzyme solution was diluted with $25 \mathrm{mM}$ $\mathrm{NH}_{4} \mathrm{HCO}_{3}$ ) was added to each tube and slightly centrifuged. The sample was freeze-dried into a powder. 


\subsection{LC-MS/MS Analysis}

The lyophilized samples were dissolved in $20 \mu \mathrm{L}$ of $2 \%$ methanol and $0.1 \%$ formic acid (FA) by centrifugation at $1000 \times g$ for $20 \mathrm{~min}$ and the supernatant was collected. Mass spectrometry (MS) data were acquired with Q Exactive (ThermoFinnigan, San Jose, CA, USA). Briefly, loading peptides onto a reverse phase trap column (Thermo Scientific Acclaim PepMap100, $100 \mu \mathrm{m} \times 2 \mathrm{~cm}$, nano Viper C18) that was pre-equilibrated with $0.1 \%$ FA. An analytical column (Thermo Scientific Easy Column, $12 \mathrm{~cm}$ long, $75 \mu \mathrm{m}$ inner diameter, $3 \mu \mathrm{m}$ resin) was used to separate components with a linear gradient of buffer $B$ $(100 \% v / v$ acetonitrile and $0.1 \% v / v$ formic acid) at a flow rate of $3 \mu \mathrm{L}$ per min for $8 \mathrm{~min}$. The separation flow rate was $600 \mathrm{~nL}$ per min.

\subsection{Data Analysis}

Specific proteins were analyzed according to the Proteome Discoverer 2.4.1.15. The raw file of the mass spectrum was identified and analyzed using the commercial software, MaxQuant (Thermo Fisher Scientific, Waltham, MA, USA). The search parameters were as follows: value of the enzyme was trypsin, static modification was $\mathrm{C}$-carboxyamidomethylation (57.021 Da), dynamic modification was oxidation (M), species was F. hepatica, mass tolerance of the precursor ion was $\pm 15 \mathrm{ppm}$, fragment ion mass tolerance was $\pm 0.5 \mathrm{Da}$, and the protein false discovery rate (FDR) was set at 0.01 . The maximum number of missed cleavages was 2. The Kyoto Encyclopedia of Genes and Genomes (KEGG) analysis of the specific proteins of F. hepatica was performed to select the most significant pathway and to analyze the relationship between the abundance of specific proteins of different pathways and the different periods of infection.

\section{Results and Discussion}

There are cases of the human infection, fascioliasis, in 56 countries, mainly in Bolivia, Peru, Egypt, Portugal and China [20]. Fascioliasis not only seriously affects the development of animal husbandry, but also poses a threat to human health. Therefore, the prevention and control of fascioliasis are of utmost importance. There is a clear need and global interest in the development of improved methods for controlling fascioliasis. We collected the F. hepatica metacercariae from the Galba pervia (Figure A1A). The results of the fecal examination along with the morphology of the eggs are shown in Figure A1B. There were pathological changes in the liver and various nodules could be seen in (Figure A1C). F. hepatica was collected (Figure A1D). Sheep infected with F. hepatica were successfully established. The albendazle pretreatment was taken to remove other helminths and that only Fasciola hepatica eggs were found following facial examination. The serum will be specific which guarantees the accuracy of the data we obtained. An immunoproteomic approach was used to identify the proteins secreted by $F$. hepatica, specifically using infection serum to pull down the FhESPs that are likely to be involved in host-parasite interactions. SDS-PAGE was used to confirm the results of the Co-IP assay (Figure 1). The results indicated that the antibodies from the serum of different infection periods could recognize and pull down specific proteins from FhESPs. The figures about proteins which are available seem very low given the SDS-PAGE because $F$. gigantica sera and negative serum were removed from the analysis. The proteins we expected to obtain need to exist in $F$. hepatica but not in F. gigantica sera, and are specific as compared with the negative serum. The majority of proteins had molecular weights ranging from 10 to $170 \mathrm{kDa}$. 


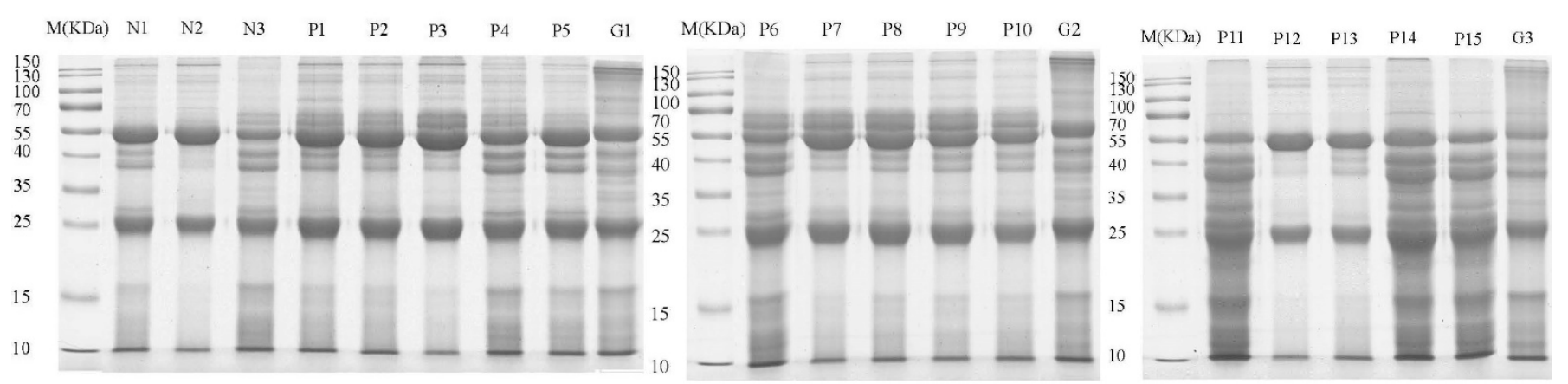

Figure 1. The sodium dodecyl sulfate-polyacrylamide gel electrophoresis (SDS-PAGE) analysis of samples with the sheep serum from different infection periods co-cultured with the F. hepatica excretory and secretory products (FhESPs) and the serum with F. gigantica. Line N1 N3: proteins pulled down by three negative sheep serum with F. hepatica. Line P1 P5: proteins pulled down by the first infected sheep serum of 3 days post-infection (dpi), $7 \mathrm{dpi}, 21 \mathrm{dpi}, 63 \mathrm{dpi}$ and $112 \mathrm{dpi}$ with F. hepatica. Line G1: proteins pulled down by the first F. gigantica serum. Line P6 P10: proteins pulled down by the second sheep serum of $3 \mathrm{dpi}, 7 \mathrm{dpi}, 21 \mathrm{dpi}, 63 \mathrm{dpi}$ and $112 \mathrm{dpi}$ with F. hepatica. Line G2: proteins pulled down by the second F. gigantica serum. Line P11 P15: proteins pulled down by the third sheep serum of $3 \mathrm{dpi}, 7 \mathrm{dpi}, 21 \mathrm{dpi}, 63 \mathrm{dpi}$ and $112 \mathrm{dpi}$ with F. hepatica. Line G3: proteins pulled down by the third F. gigantica serum.

Comparing all results, we found that there were $30,22,23,27$, and 22 proteins identified at $3 \mathrm{dpi}, 7 \mathrm{dpi}, 21 \mathrm{dpi}, 63 \mathrm{dpi}$, and $112 \mathrm{dpi}$, respectively, according to the LC-MS/MS analysis, but only 12 proteins were co-purified in all five periods (Figure 2, Table 1). The abundance of proteins are all well (Table A1). Some of these proteins are currently not annotated. However, some of the annotated proteins, such as acyl-coenzyme A thioesterase 8 , are related to metabolism, while others may have different functions. In addition, upon comparing these protein datasets for different infection periods with those of $F$. gigantica, we found that there was an overlap in the protein expression levels among these samples, and the relationships of these pulled down proteins was summarized in an upsetvenn diagram (Figure 3). This indicated that six proteins might take part in the host-parasite interactions during the whole infection period, and they have good specificity compared to the proteins of F. gigantica. These six proteins are the last six proteins in Table 1. Two proteins were unannotated. The alpha subunit of casein kinase II is related to ATP-binding and belongs to the protein kinase superfamily. The casein kinase 2 alpha subunit (CK2a) is involved in the activation of muscle-specific gene programs. The CK2 subunits exert specific and coordinated functions in skeletal muscle differentiation and show fusogenic activity [21]. HIV Tat-specific factor 1 protein, which belongs to the HTATSF1 family, is related to RNA binding. Tat-SF1 is not required for regulating HIV-1 transcription, however, it is required to maintain the ratios of different classes of HIV-1 transcripts [22]. The fructose-bisphosphatase protein belongs to the fructose-1,6-bisphosphatase (FBPase) class 1 family, which is related to the fructose 1,6-bisphosphate-1-phosphatase activity (Table 1). The proteins of the Anisakis proteomes were characterized by label-free quantification and functional analysis, and proteins involved in many essential biological mechanisms, such as parasite survival, were identified, among which is the fructose 1,6-bisphosphatase [23]. The 40S ribosomal protein, S3a, is a structural constituent of the ribosome, which belongs to the eukaryotic ribosomal protein eS1 family. These proteins were detected in F. hepatica but not in F. gigantica, where they took part in the host-parasite interactions. The Kyoto Encyclopedia of Genes and Genomes (KEGG) is a reference knowledge base for the biological interpretation of large-scale molecular datasets [24]. KEGG revealed that the specific proteins were mainly involved in the metabolism and regulation of genetic activity and the proteins related to signal transduction and metabolism play important roles in the interaction between F. hepatica and the host. We also found that the abundance of proteins was different in each period of infection (Figure 4). The 40S ribosomal protein, S3a, which is related to the ribosomal pathway, was relatively higher and more stable than other proteins. CK2a was highest at $112 \mathrm{dpi}$ in the ribosome biogenesis pathway and the fructose- 
bisphosphatase protein was highest at $64 \mathrm{dpi}$ in the glycolysis/gluconeogenesis pathway in eukaryotes. Thus, specific proteins could be good candidates for further diagnostic studies of infections. Proteins with high expression, including the 40S ribosomal protein S3a, CK2a, and the fructose-bisphosphatase protein may be better for further diagnostic studies.

Table 1. The Fasciola hepatica excretory and secretory products (FhESPs) which were detected in the sheep post-infection in all periods.

\begin{tabular}{|c|c|c|c|c|c|c|c|c|}
\hline Protein Description & Species & $\begin{array}{l}\text { Genome } \\
\text { Mapping } \\
\text { Gene ID }^{\mathrm{a}}\end{array}$ & Peptides & $\begin{array}{l}\text { Unique } \\
\text { Peptides }\end{array}$ & $\begin{array}{l}\text { Cover } \\
\text { Percent }\end{array}$ & $\begin{array}{l}\text { GeneBank } \\
\text { Bank ID }\end{array}$ & $\begin{array}{c}\text { MW } \\
\mathbf{b}(\mathrm{KDa})\end{array}$ & calc. $\mathrm{pI}^{\mathrm{c}}$ \\
\hline \multirow{2}{*}{$\begin{array}{l}\text { Uncharacterized protein } 1 \\
\text { Heparosan-N-sulfate- } \\
\text { glucuronate } \\
\text { 5-epimerase }\end{array}$} & Fasciola hepatica & D915_008782 & 2 & 2 & 12 & THD20526.1 & 25.9 & 6.24 \\
\hline & Fasciola hepatica & D915_004542 & 1 & 1 & 1 & THD24727.1 & 80 & 9.03 \\
\hline \multirow{3}{*}{$\begin{array}{c}\text { Synaptophysin } \\
\text { Uncharacterized protein } 2 \\
\text { Acyl-coenzyme A } \\
\text { thioesterase } 8\end{array}$} & Fasciola hepatica & D915_006334 & 1 & 1 & 3 & THD22918.1 & 26.1 & 5.34 \\
\hline & Fasciola hepatica & D915_001733 & 1 & 1 & 4 & THD27516.1 & 15.5 & 7.03 \\
\hline & Fasciola hepatica & D915_007699 & 1 & 1 & 2 & THD21305.1 & 37.1 & 6.87 \\
\hline \multicolumn{9}{|l|}{ ATP-dependent Clp protease } \\
\hline $\begin{array}{l}\text { ATP-binding subunit clpX } \\
\text { mitochondrial }\end{array}$ & Fasciola hepatica & D915_009354 & 1 & 1 & 1 & THD19712.1 & 60.5 & 6.35 \\
\hline Uncharacterized protein 3 & Fasciola hepatica & D915_000294 & 1 & 1 & 2 & THD28860.1 & 30.9 & 6.99 \\
\hline Uncharacterized protein 4 & Fasciola hepatica & D915_005102 & 1 & 1 & 1 & THD24171.1 & 55.6 & 8.76 \\
\hline \multirow{2}{*}{$\begin{array}{c}\text { 40S ribosomal protein S3a } \\
\text { HIV Tat-specific factor } 1 \\
\text { protein }\end{array}$} & Fasciola hepatica & D915_000892 & 1 & 1 & 3 & THD28280.1 & 25.3 & 9.85 \\
\hline & Fasciola hepatica & D915_000726 & 1 & 1 & 1 & THD28435.1 & 67.5 & 5 \\
\hline \multirow{2}{*}{$\begin{array}{c}\text { Fructose-bisphosphatase } \\
\text { Alpha subunit of casein } \\
\text { kinase II }\end{array}$} & Fasciola hepatica & D915_007520 & 1 & 1 & 5 & THD21694.1 & 29.1 & 6.16 \\
\hline & Fasciola hepatica & D915_004801 & 1 & 1 & 2 & THD24445.1 & 44.2 & 8.48 \\
\hline
\end{tabular}

${ }^{a}$ The genome mapping gene ID only relates to Fasciola hepatica. ${ }^{\mathrm{b}}$ Molecular weight of the leading protein sequence contained in the protein group. ${ }^{c}$ Theoretical isoelectric point.

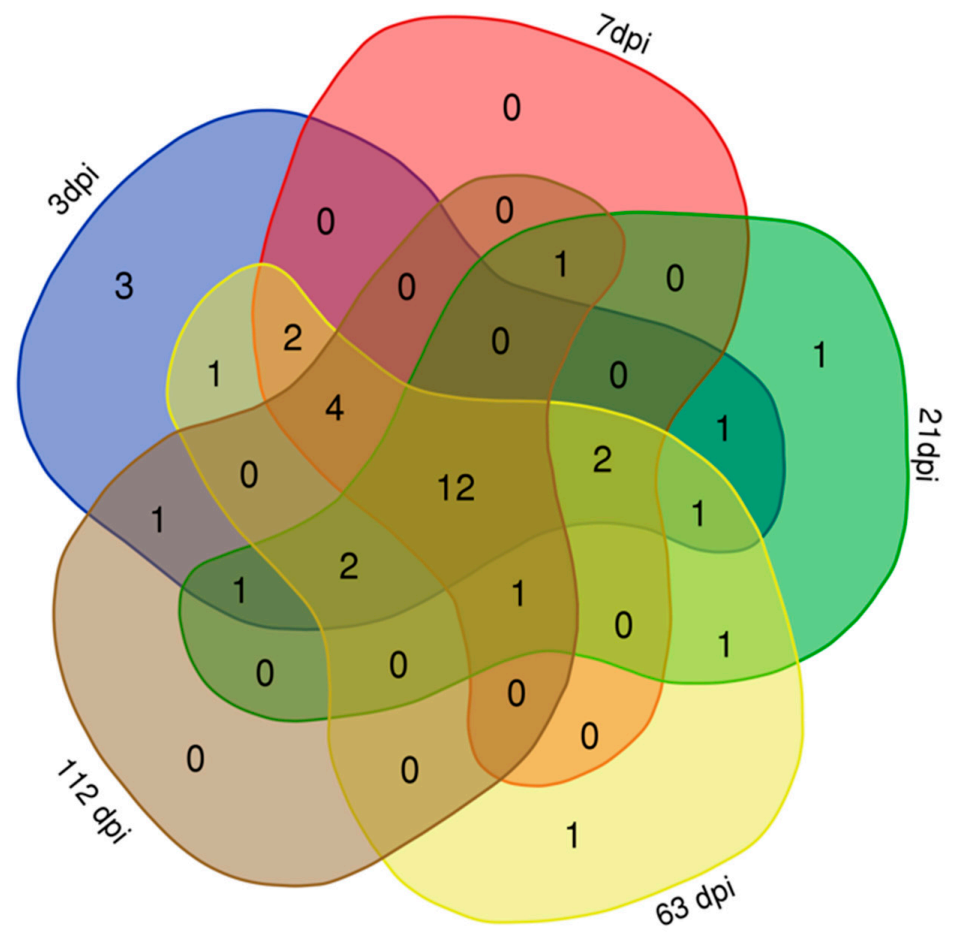

Figure 2. Total proteins that were identified to be binding to the sheep serum at: 3 days post-infection (dpi) with F. hepatica (blue); 7 dpi with F. hepatica (pink); 21 dpi with F. hepatica (green); 63 dpi with F. hepatica (yellow); and 112 dpi with F. hepatica (grey). 


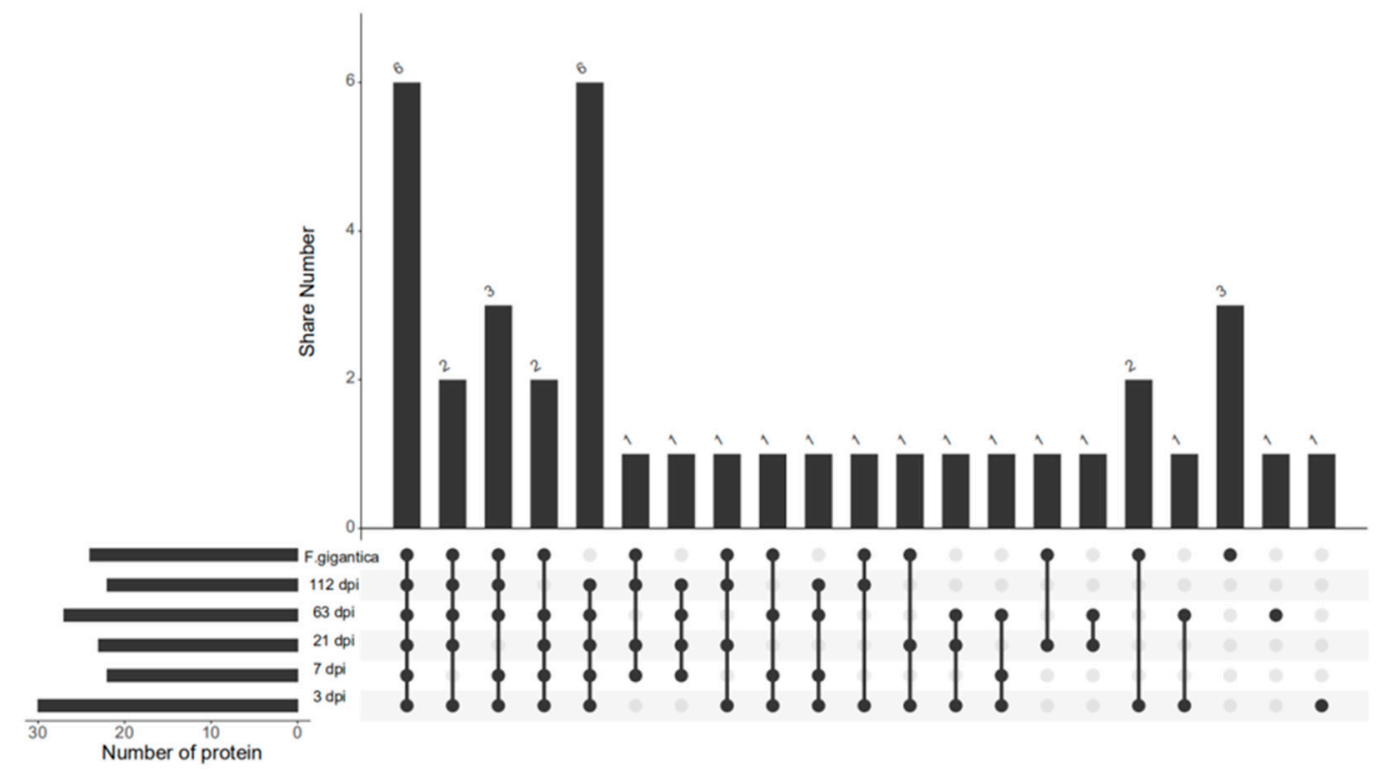

Figure 3. Total proteins that were identified to be binding to the sheep serum at 3 days post-infection (dpi); $7 \mathrm{dpi} ; 21 \mathrm{dpi}$; $63 \mathrm{dpi}$; and $112 \mathrm{dpi}$ with F. hepatica and the total proteins that were identified to be binding to the sheep serum with F. gigantica.

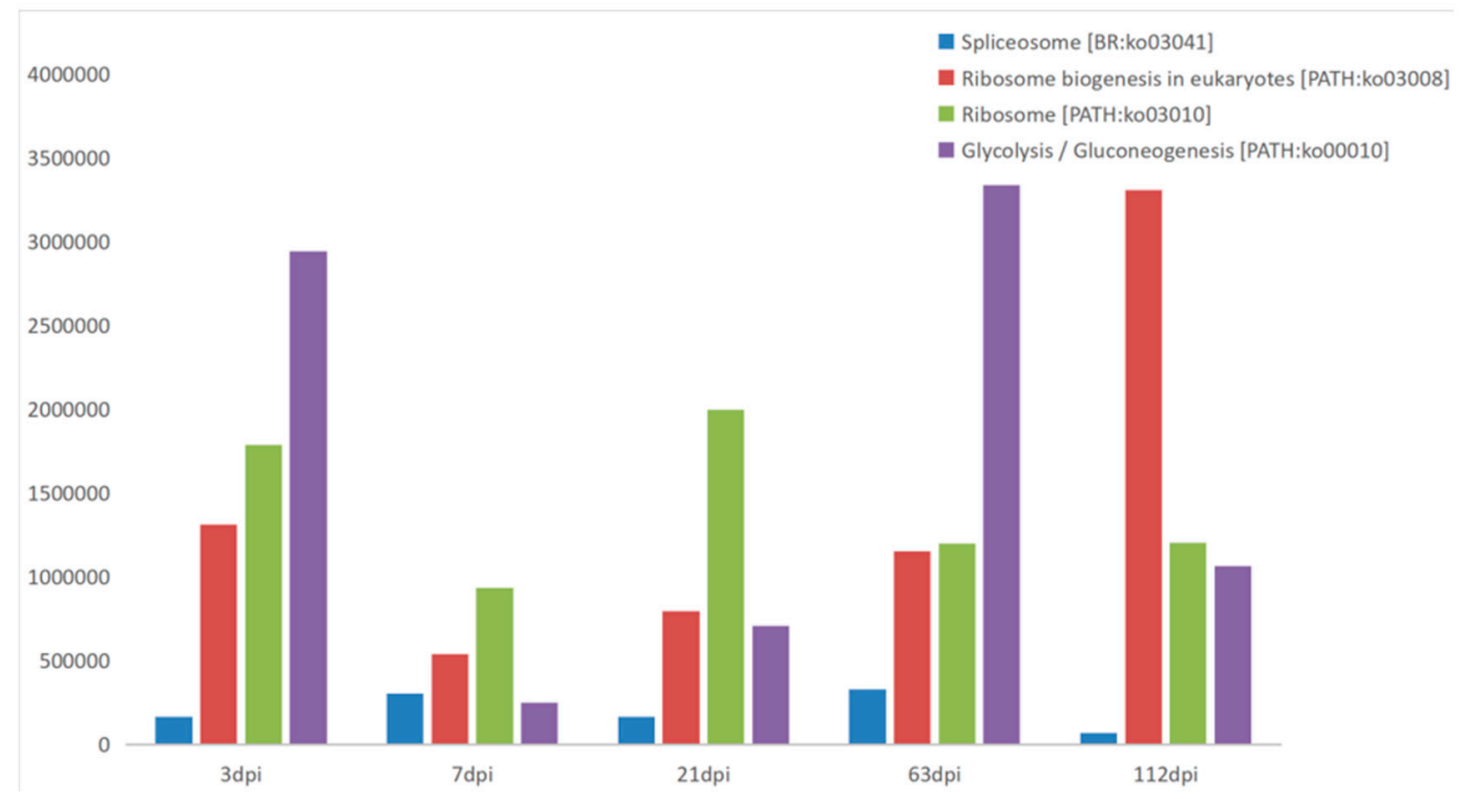

Figure 4. The selected signal path in the Kyoto Encyclopedia of Genes and Genomes (KEGG) database is displayed with different colors. Different periods are displayed by the horizontal coordinates. The abundance expressed by specific proteins is displayed by the longitudinal coordinates. 
ESPs play important roles during the development of parasites, especially in hostparasite interactions, and many ESPs of Fasciola spp. have been shown to evade and defend against the host immune responses [15]. FhESPs can downmodulate the proliferation of spleen mononuclear cells [25] and induce immunomodulatory effects on macrophages by inducing T-cell activity via the selective upregulation of programmed death-ligand 2 (PD-L2) expression in a Dectin-1 dependent manner [26]. ESPs from $F$. hepatica are directly exposed to the host immune system and are widely used as antigens in serological assays. MM3-ELISA uses monoclonal antibodies to capture protein fragments (mainly cathepsin L1 and L2) of molecular weights 7-40 kDa from FhESPs. The sensitivity and specificity of this kit are $99 \%$ and $100 \%$, respectively [6,27]. However, the cost performance of this kit was unsatisfactory. The proteins have been purified as part of complexes by Co-IP. Although the mixture of antibody and antigen is extracted, the antibody complex is incubated with the antigen derived from F. hepatica, then the F. hepatica can be identified in the search library by MS. However, whether the identified proteins screened in this study have high specificity and sensibility still needs to be proven by subsequent experiments including Western blot and ELISA. If they have good reaction in the following study, they have good antigenicity. Once some of them can be purified and have good combination with positive serum, then these can provide a good foundation for developing new immunological diagnostic methods. Many proteins were identified in this study, however, the functions of most of them are unknown. Moreover, the key genes involved in the interplay between the host and parasite interactions have not yet been identified. This highlights the central role played by ESPs in the protection of $F$. hepatica from the host immune responses. Therefore, this study lays a foundation for further studies on the interactions between $F$. hepatica and the host as well as the diagnosis of $F$. hepatica.

Author Contributions: Conceptualization, all authors; writing—original draft preparation, all authors; writing—-review and editing, all authors; preparation of figures, Z.L.; supervision, Y.-Y.C.; funding acquisition, C.-R.W. All authors have read and agreed to the published version of the manuscript.

Funding: This work was supported by the National Key Research and Development Program of China (2017YFD0501200), the National Natural Science Foundation of China (Grant No. 31672399) and the grant from Heilongjiang Bayi Agricultural University Support Program for San Heng San Zong (TDJH202002).

Institutional Review Board Statement: This study was approved by the Animal Health, Animal Care and Use Committee of Heilongjiang BAYI Agricultural University. The study was conducted according to the guidelines of the Declaration of Helsinki, and ap-proved by the Institutional Review Board (or Ethics Committee) of NAME OF INSTITUTE (pro-tocol code HBAU-2018002 and approval on April 10, 2018).

Informed Consent Statement: Not applicable.

Data Availability Statement: The data presented in this study are available on request from the corresponding author.

Acknowledgments: We thank the Xing-quan Zhu of Laboratory Animal Center of Lanzhou Veterinary Research Institute of the Chinese Academy of Agriculture Sciences for providing the serum of $F$. gigantica.

Conflicts of Interest: The authors declare that there are no competing interests. 


\section{Appendix A}

A

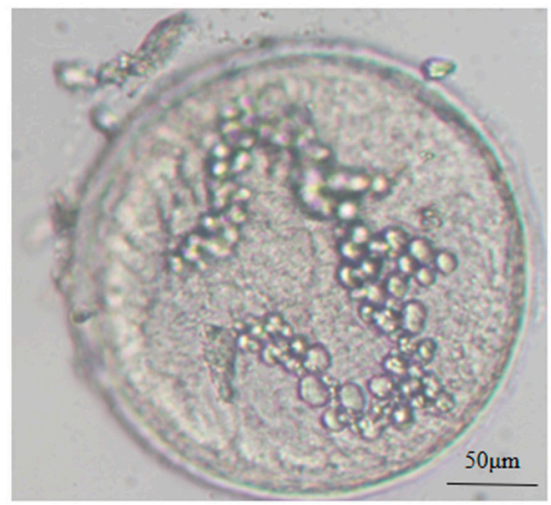

C

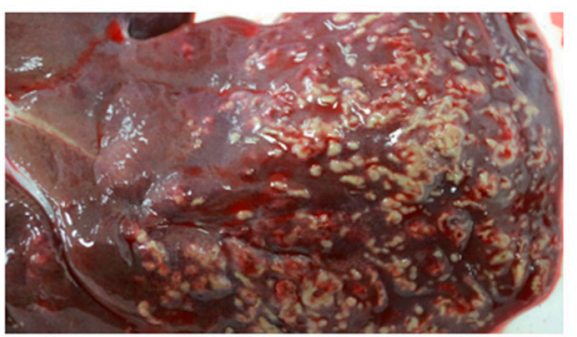

B

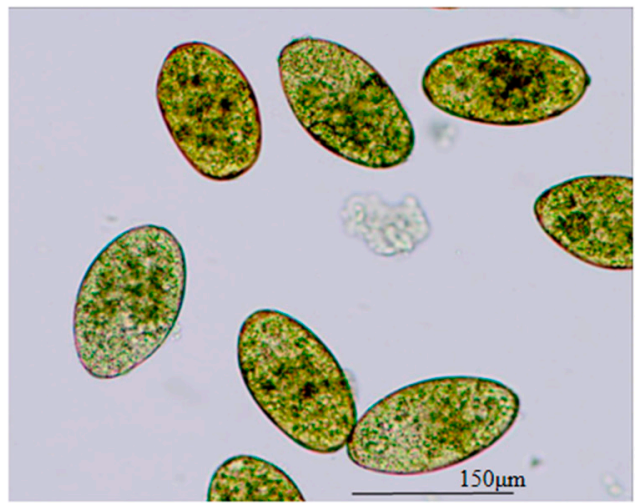

D

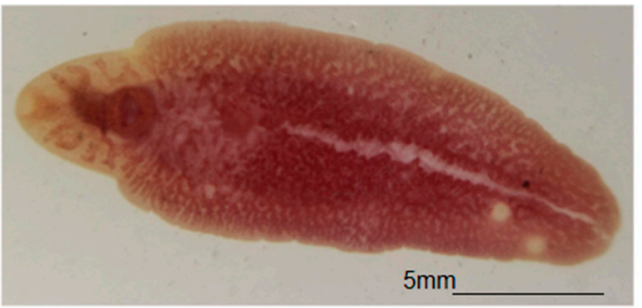

Figure A1. Infection characteristics: (A) Metacercariae used to infect sheep; (B) F. hepatica eggs observed under an optical microscope; (C) the liver of sheep infected with F. hepatica; (D) the $F$. hepatica collected from the liver of sheep previously infected with $F$. hepatica.

\section{Appendix B}

Table A1. The proteins derived from each period and their abundance.

\begin{tabular}{|c|c|c|c|c|c|c|}
\hline \multirow{2}{*}{ GenBank } & \multirow{2}{*}{ Protein Description } & \multicolumn{5}{|c|}{ Abundance } \\
\hline & & 3 dpi & $7 \mathrm{dpi}$ & $21 \mathrm{dpi}$ & $63 \mathrm{dpi}$ & $112 \mathrm{dpi}$ \\
\hline THD21074.1 & Gelsolin repeat protein & $24,022.21289$ & - & - & - & - \\
\hline THD22536.1 & Fructose-bisphosphate aldolase & $86,937.625$ & - & $172,559.1563$ & - & - \\
\hline THD27725.1 & Uncharacterized protein & $553,797.5$ & - & $793,536.625$ & - & $504,179.2188$ \\
\hline THD23308.1 & Dynein light chain & $11,747.43164$ & $14,691.50586$ & - & 7394.90625 & $21,221.78906$ \\
\hline THD24816.1 & Serpin protein & $1,646,911.188$ & - & $134,091.1719$ & $333,078.8438$ & $906,792.8125$ \\
\hline THD27667.1 & Phosphoglucomutase & $341,188.4844$ & - & - & $417,641.75$ & - \\
\hline THD20135.1 & Legumain & $2,782,378$ & - & - & - & $17,424,414.5$ \\
\hline THD20526.1 & Uncharacterized protein & $77,763.89844$ & $53,412.98438$ & $79,610.59375$ & $44,011.75781$ & $116,365.3672$ \\
\hline THD22651.1 & Glucose-6-phosphate 1-dehydrogenase & $161,910.9531$ & - & $170,645.4531$ & $536,310.6875$ & - \\
\hline THD26293.1 & Annexin & $488,116.9375$ & - & - & - & - \\
\hline THD21694.1 & Fructose-bisphosphatase & $2,940,358.5$ & $250,116.7344$ & $706,553.3125$ & $3,337,365.5$ & $1,063,860$ \\
\hline THD23211.1 & Tubulin alpha chain & $330,362.1563$ & - & $130,189.7266$ & $768,367.25$ & $243,900.8594$ \\
\hline THD28435.1 & HIV Tat-specific factor 1 protein & $163,905.5781$ & $302,068.5313$ & $164,833.7969$ & $328,743.75$ & $67,329.42188$ \\
\hline THD24727.1 & $\begin{array}{l}\text { Heparosan-N-sulfate-glucuronate } \\
\text { 5-epimerase }\end{array}$ & $409,968.5$ & $85,834.78125$ & $160,129.6875$ & 155,940 & $156,170.7813$ \\
\hline THD22918.1 & Synaptophysin & $119,084.1016$ & $68,156.35938$ & $103,948.9063$ & $222,138.8828$ & $87,811.85156$ \\
\hline THD28852.1 & Ubiquitin-conjugating enzyme & $668,924.625$ & $118,031.6016$ & NA & $505,793.9375$ & $343,043.6172$ \\
\hline THD27516.1 & Uncharacterized protein & $4,501,626$ & $926,071.1875$ & $2,201,982.75$ & $1,899,086.625$ & $1,882,076.625$ \\
\hline THD24445.1 & Alpha subunit of casein kinase II & $1,313,028.719$ & $537,602.3906$ & $793,033.75$ & $1,153,075.125$ & $3,306,170.313$ \\
\hline THD19712.1 & $\begin{array}{l}\text { ATP-dependent Clp protease ATP-binding } \\
\text { subunit clpX mitochondrial }\end{array}$ & $3,510,484.25$ & - & - & - & - \\
\hline THD22278.1 & Tubulin-tyrosine ligase-like protein 9 & $473,730.9688$ & - & - & - & - \\
\hline THD28860.1 & Uncharacterized protein & $49,954,940$ & $14,922,535$ & $18,942,136$ & $40,814,652$ & $38,499,836$ \\
\hline THD26528.1 & rRNA-processing protein FCF1 isogeny & $263,285.7188$ & $110,388.4141$ & - & $325,662.4688$ & - \\
\hline THD25229.1 & Hexosyltransferase & $100,760.8984$ & $29,143.81445$ & - & $26,410.00195$ & - \\
\hline THD22369.1 & Uncharacterized protein & $188,394.8125$ & $62,918.48828$ & - & $93,628.02344$ & $101,414.2734$ \\
\hline THD24171.1 & Uncharacterized protein & $499,705.5625$ & $93,921.17969$ & $293,650.7813$ & $1,253,055.875$ & $694,243.1875$ \\
\hline THD21345.1 & Uncharacterized protein & 389,435 & $503,797.4063$ & $2,321,797.25$ & $602,599.5625$ & - \\
\hline
\end{tabular}


Table A1. Cont

\begin{tabular}{|c|c|c|c|c|c|c|}
\hline \multirow{2}{*}{ GenBank } & \multirow{2}{*}{ Protein Description } & \multicolumn{5}{|c|}{ Abundance } \\
\hline & & $3 \mathrm{dpi}$ & $7 \mathrm{dpi}$ & $21 \mathrm{dpi}$ & $63 \mathrm{dpi}$ & $112 \mathrm{dpi}$ \\
\hline THD21879.1 & Inhibitor of apoptosis protein & $1,977,777.75$ & $1,209,314.875$ & $1,346,054$ & $1,589,138.125$ & - \\
\hline THD28280.1 & $40 \mathrm{~S}$ ribosomal protein $\mathrm{S} 3 \mathrm{a}$ & $1,786,953.672$ & $934,144.1875$ & $1,994,597.219$ & $1,198,627.375$ & $1,202,573$ \\
\hline THD21305.1 & Acyl-coenzyme A thioesterase 8 & $1,959,986.75$ & $162,016.5469$ & $185,430.125$ & $1,942,750.313$ & $1051,204.156$ \\
\hline THD28550.1 & Uncharacterized protein & $335,545.5625$ & $39,628.06641$ & - & $181,182.0156$ & $118,531.6094$ \\
\hline THD28078.1 & Guanine nucleotide exchange factor & - & $44,768.47266$ & $466,165.8438$ & - & $236,903.5234$ \\
\hline THD19712.1 & $\begin{array}{l}\text { ATP-dependent Clp protease ATP-binding } \\
\text { subunit clpX mitochondrial }\end{array}$ & - & $221,215.0469$ & $985,376.8125$ & $2,183,246.25$ & $2,075,125.5$ \\
\hline THD20617.1 & ATP-dependent DNA helicase & - & $417,392.3438$ & $442,980.4375$ & $286,577.8125$ & $481,421.625$ \\
\hline THD19133.1 & VIT domain-containing protein & - & - & $93,653.66406$ & $51,209.55859$ & - \\
\hline THD19784.1 & ML domain-containing protein & - & - & $65,019.27344$ & - & - \\
\hline THD28903.1 & Isocitrate dehydrogenase [NADP] & - & - & - & $770,771.625$ & - \\
\hline
\end{tabular}

\section{References}

1. Mas-Coma, S.; Bargues, M.D.; Valero, M.A. Human fascioliasis infection sources, their diversity, incidence factors, analytical methods and prevention measures. Parasitology 2020, 145, 1665-1699. [CrossRef]

2. Mehmood, K.; Zhang, H.; Sabir, A.J.; Abbas, R.Z.; Ijaz, M.; Durrani, A.Z.; Saleem, M.H.; Ur-Rehman, M.; Iqbal, M.K.; Wang, Y.; et al. A review on epidemiology, global prevalence and economical losses of fasciolosis in ruminants. Microb. Pathog. 2017, 109, 253-262. [CrossRef] [PubMed]

3. Pinilla, J.C.; Florez-Muñoz, A.A.; Uribe-Delgado, N. Prevalence and risk factors associated with liver fluke Fasciola hepatica in cattle and sheep in three municipalities in the Colombian Northeastern Mountains. Vet. Parasitol. Reg. Stud. Rep. 2020, $19,100364$. [CrossRef]

4. Machicado, C.; Machicado, J.D.; Maco, V.; Terashima, A.; Marcos, L.A. Association of Fasciola hepatica Infection with Liver Fibrosis, Cirrhosis, and Cancer: A Systematic Review. PLoS. Negl. Trop. Dis. 2016, 10, e0004962. [CrossRef]

5. Abuzeid, A.M.I.; Zhou, X.; Huang, Y.; Li, G. Twenty-five-year research progress in hookworm excretory/secretory products. Parasit. Vectors 2020, 13, 136. [CrossRef] [PubMed]

6. MartÍnez-Pérez, J.M.; Robles-Pérez, D.; Rojo-VÁzquez, F.A.; Martínez-Valladares, M. Comparison of three different techniques to diagnose Fasciola hepatica infection in experimentally and naturally infected sheep. Vet. Parasitol. 2012, 190, 80-86. [CrossRef]

7. Ma, Z.; Mutashar-Alhameed, A.M.; Kaminga, A.C.; Lu, B.; Li, X.; Zhang, J.; Wu, X. Bioinformatics of excretory/secretory proteins of Toxoplasma gondii strain ME49. Microb. Pathog. 2020, 140, 103951. [CrossRef]

8. Gupta, S.C.; Yadav, S.C. Emergence of Fasciola gigantica cercariae from naturally infected Lymnaea auricularia. J. Parasit. Dis. 1994, 18, 53-56.

9. Rotmans, J.P.; Van, M.J.; Looze, M.; Mooij, G.W.; Deelder, A.M. Schistosoma mansoni: Use of antigens from excretions and secretions in immunodiagnosis. Exp. Parasitol. 1981, 52, 319-330. [CrossRef]

10. Chehayeb, J.F.; Robertson, A.P.; Martin, R.J.; Geary, T.G. Proteomic analysis of adult Ascaris suum fluid compartments and secretory products. PLoS. Negl. Trop. Dis. 2014, 8, e2939. [CrossRef]

11. Gadahi, J.; Yongqian, B.; Ehsan, M.; Zhang, Z.; Wang, S.; Yan, R.F.; Song, X.K.; Xu, L.X.; Li, X.R. Haemonchus contortus excretory and secretory proteins (HcESPs) suppress functions of goat PBMCs in vitro. Oncotarget 2016, 7, 35670-35679. [CrossRef]

12. Sotillo, J.; Sanchez-Flores, A.; Cantacessi, C.; Harcus, Y.; Pickering, D.; Bouchery, T.; Camberis, M.; Tang, S.C.; Giacomin, P.; Mulvenna, J.; et al. Secreted proteomes of different developmental stages of the gastrointestinal nematode Nippostrongylus brasiliensis. Mol. Cell. Proteom. 2014, 13, 2736-2751. [CrossRef]

13. Li, M.C.; Pan, J.D.; Fan, Z.H.; Chen, W.L.; Chen, C.L.; Wu, H.L.; Li, T.G.; Sun, Y.J.; Du, L.Y. Changes of protein components in small cell lung cancer H446 cells treated with ESPs of Trichinella spiralis. Chin. J. Zoonoses 2020, 36, 821-826.

14. Gourbal, B.E.; Guillou, F.; Mitta, G.; Sibille, P.; Thèron, A.; Pointier, J.P.; Coustau, C. Excretory-secretory products of larval Fasciola hepatica investigated using a two-dimensional proteomic approach. Mol. Biochem. Parasitol. 2008, 161, 63-66. [CrossRef] [PubMed]

15. Jefferies, J.R.; Campbell, A.M.; van-Rossum, A.; Barrett, J.; Brophy, P.M. Proteomic analysis of Fasciola hepatica excretory secretory products. Proteomics 2001, 1, 1128-1132. [CrossRef]

16. Huang, S.Y.; Yue, D.M.; Hou, J.L.; Zhang, X.X.; Zhang, F.K.; Wang, C.R.; Zhu, X.Q. Proteomic analysis of Fasciola gigantica excretory and secretory products (FgESPs) interacting with buffalo serum of different infection periods by shotgun LC-MS/MS. Parasitol. Res. 2019, 118, 453-460. [CrossRef]

17. Cwiklinski, K.; Dalton, J.P.; Dufresne, P.J.; La-Course, J.; Williams, D.J.; Hodgkinson, J.; Paterson, S. The Fasciola hepatica genome: Gene duplication and polymorphism reveals adaptation to the host environment and the capacity for rapid evolution. Genome Biol. 2015, 16, 71. [CrossRef] [PubMed]

18. Choi, Y.J.; Fontenla, S.; Fischer, P.U.; Le, T.H.; Costábile, A.; Blair, D.; Brindley, P.J.; Tort, J.F.; Cabada, M.M.; Mitreva, M. Adaptive Radiation of the Flukes of the Family Fasciolidae Inferred from Genome-Wide Comparisons of Key Species. Mol. Biol. Evol. 2020, 37, 84-99. [CrossRef] 
19. Novobilsky, A.; Kasny, M.; Mikes, L.; Kovarcik, K.; Koudela, B. Humoral immune responses during experim ental infection with Fascioloides magna and Fasciola hepatica in goats and comparison. Parasitol. Res. 2007, 101, 357-364. [CrossRef] [PubMed]

20. Rim, H.J.; Faraq, H.F.; Sornmani, S.; Cross, J.H. Food-borne trematodes: Ignored or emerging. Parasitol. Today 1994, 10, 207-209. [CrossRef]

21. Salizzato, V.; Zanin, S.; Borgo, C.; Lidron, E.; Salvi, M.; Rizzuto, R.; Pallafacchina, G.; Donella-Deana, A. Protein kinase CK2 subunits exert specific and coordinated functions in skeletal muscle differentiation and fusogenic activity. FASEB J. 2019, 33, 10648-10667. [CrossRef]

22. Miller, H.B.; Saunders, K.O.; Tomaras, G.D.; Garcia-Blanco, M.A. Tat-SF1 is not required for Tat transactivation but does regulate the relative levels of unspliced and spliced HIV-1 RNAs. PLoS ONE 2009, 27, e5710. [CrossRef] [PubMed]

23. Kochanowski, M.; Dabrowska, J.; Różycki, M.; Karamon, J.; Sroka, J.; Cencek, T. Proteomic Profiling Reveals New Insights into the Allergomes of Anisakis simplex, Pseudoterranova decipiens, and Contracaecum osculatum. J. Parasitol. 2020, 106, 572-588. [CrossRef]

24. Kanehisa, M.; Sato, Y. KEGG Mapper for inferring cellular functions from protein sequences. Protein. Sci. 2020, 29 , 28-35. [CrossRef] [PubMed]

25. Cervi, L.; Masih, D.T. Inhibition of spleen cell proliferative response to mitogens by excretory-secretory antigens of Fasciola hepatica. Int. J. Parasitol. 1997, 27, 573-579. [CrossRef]

26. Guasconi, L.; Chiapello, L.S.; Masih, D.T. Fasciola hepatica excretorysecretory products induce CD4+T cell anergy via selective upregulation of PD-L2 expression on macrophages in a Dectin-1 dependent way. Immunobiology 2015, 220, 934-939. [CrossRef] [PubMed]

27. Mezo, M.; Gonzalez-Warleta, M.; Castro-Hermida, J.A.; Muiño, L.; Ubeira, F.M. Field evaluation of the MM3-SERO ELISA for detection of anti-Fasciola IgG antibodies in milk samples from individual cows and bulk milk tanks. Parasitol. Int. 2010, 59, 610-615. [CrossRef] 